\title{
Entrelacs
}

Cinéma et audiovisuel

HS | 2012

Le post-humain et les enjeux du sujet

\section{Le sujet de la création}

\section{Xavier Lambert}

\section{OpenEdition}

\section{Journals}

Édition électronique

URL : http://journals.openedition.org/entrelacs/294

DOI : 10.4000/entrelacs.294

ISSN : 2261-5482

Éditeur

Éditions Téraèdre

Édition imprimée

Date de publication : 2 février 2012

ISBN : 978-2296567177

ISSN : 1266-7188

Référence électronique

Xavier Lambert, « Le sujet de la création », Entrelacs [En ligne], HS | 2012, mis en ligne le 01 août 2012, consulté le 03 mai 2019. URL : http://journals.openedition.org/entrelacs/294 ; DOI : 10.4000/ entrelacs.294

Ce document a été généré automatiquement le 3 mai 2019.

Tous droits réservés 


\section{Le sujet de la création}

\section{Xavier Lambert}

1 Le texte complet de cet article est publié dans l'ouvrage :

Post humain et les enjeux du sujet

Editeur : L'HARMATTAN (2 février 2012)

Collection Ouverture Philosophique

ISBN-10 : 2296567177

ISBN-13 : 978-2296567177

\section{RÉSUMÉS}

Si nous pouvons admettre que le post-humain se déploie dans le dépassement de l'humain, il convient de remarquer que l'humain dont il est question est celui qui a été défini conceptuellement à partir de la Renaissance. C'est donc bien de l'humain en tant que point de référence à l'apperception et à la définition du monde qu'il s'agit. En ce qui concerne la création artistique, le concept d'humain permet de poser celui du sujet créateur (d'où la naissance de l'autoportrait, par exemple). La post-modernité va faire émerger une pensée systémique, qui dilue l'humain dans la pensée des systèmes en même temps que le post-industriel va exacerber l'individu au détriment du sujet. Dès lors, que devient le sujet créateur ? Est-ce que le paradigme systémique, de même qu'il semble inscrire un déplacement de l'humain, inscrit par là même un déplacement du sujet créateur? Auquel cas, quelle pourrait être la nature de ce déplacement?

\section{AUTEUR}

\section{XAVIER LAMBERT}

Maître de conférences en arts plastiques, Université de Toulouse-Le Mirail 